\title{
Two Switch Forward Converter for Charging of Battery through Hybrid Charging Technique
}

\author{
Sukesh $\mathbf{A}^{\mathbf{1}}$, Gururaj $\mathbf{K}^{\mathbf{2}}$ \\ PG Scholar, Dept Electrical \& Electronics, NMAMIT, Nitte, India ${ }^{1}$ \\ Asst. Prof., Dept Electrical \& Electronics, NMAMIT, Nitte, India ${ }^{2}$
}

\begin{abstract}
This paper presents a double ended forward converter designed to charge small arrays of batteries placed in series and parallel such that high output characteristics of converter is supported. Hybrid charging technique has been used consisting 2 technique namely constant current and constant voltage respectively. This gives insight on influence of different charge profiles on batteries and on their indicators, State of Charge (SOC). The main design step for the Double ended forward converter is presented with the experimental results of the designed converter. The latter used to ensure that the battery cells will operate within their safe limits.
\end{abstract}

Keywords: State of charge (SOC), Double Ended Forward Converter, Hybrid charging technique, Battery charging.

\section{INTRODUCTION}

Power production in developed and developing countries is majorly through fossil fuels. Depletion of these fuels has led to use of renewable resources. The main problem is the storage of generated power. Hence there is a need to improve battery technology were battery management system [2] come in handy. Battery management techniques will improve the performance of the battery and which makes it a safe, reliable, and cost-efficient solution. BMS contains accurate algorithms which measures and estimates the functional status of the battery and protect the battery from hazardous and inefficient operating conditions. With improvements in power storage capability of batteries, there is a huge scope for charge controlling in battery management system. Instead of having an independent charger and a source for an individual battery an array of battery i.e. a series and parallel combination of batteries with all having the same characteristic can be charged with a single controller as well as a single source. In this paper [4], battery management system of cell monitoring and protection has been discussed. The design and testing of Lithium Ferro Phosphate (LFP) cells in a battery is done. The battery management system monitoring has been able to measure the battery parameters such as the voltage and current dynamics.

A Typical high-frequency dc-dc converter for off-line applications has been discussed in [3]. This article also provides a comprehensive solution to perform core reset, turn-off snubber, voltage-clamped and input filter functions with minimum component count.

Forward converter topology is favoured in isolated DC/DC power converter for its simplicity, flexibility to accommodate multiple isolated outputs and the easy modulation of the duty cycle for the optimized working of the circuit. Single MOSFET switch is employed in the conventional forward converter, which is primary-ground referenced for conveniently driving the gate. The drawback to this topology is that the voltage stress on the switch is the sum of the input voltage, the reflected transformer voltage, and the turn-off voltage spike caused by leakage inductance to overcome this limitation double ended forward converter has been proposed. In this paper for charge controlling is done through switched mode power supply circuit, which is a double ended forward converter. The benefits of the double ended forward converter [5] operating at high frequency for high-voltage applications as a power supply. The converter topology is characterized by simplicity, robustness, and controllability.

\section{SYSTEM DESCRIPTION}

A. Double ended forward converter

The proposed converter is shown in figure 1. For convenience purpose rectified output from full bridge rectifier has been used. The output from the solar panel with maximum power point tracking can also be used for tapping renewable resources. In double ended forward converter two MOSFET switches $S_{\mathrm{w} 1}$ and $S_{\mathrm{w} 2}$ are connected on either side of the transformer. Gating pulse to the switches is provided simultaneously. The transformer used here is a step-down transformer with diodes Din1 and Din2 shorting the switches with the opposite legs of the transformer.

When switches are turned off the current flowing in through the magnetizing inductance will cause the reversal of the primary voltage until the reverse current is caught from the dotted end of the transformer by the diode $\mathrm{D}_{\mathrm{in} 2}$. 


\author{
National Conference on Advances in Electrical Engineering \\ NMAM Institute of Technology, Nitte \\ Vol. 5, Special Issue 2, April 2017
}

The positive end of the transformer is clamped to $V_{\text {in }}$ by to diode $\mathrm{D}_{\text {in } 1}$. The maximum voltage across the MOSFET during the turning off period is $\mathrm{V}_{\text {in }}$. Energy from leakage inductance is clamped and returned through diodes $D_{\text {in1 }}$ and $D_{\text {in2 }}$ back to the source. Since there is no need to dissipate this energy there is no need for the resistive snubber or higher rating transistor. Since the inductive energy is now clamped, ringing associated with discharge of this energy through tertiary winding is eliminated hence system noise reduces. Since snubber circuit is eliminated electromagnetic interference is reduced. When switches $\mathrm{S}_{\mathrm{w} 1}$ and $\mathrm{S}_{\mathrm{w} 2}$ are turned off diodes Din1 and Din2 clamps and apply the input voltage with reverse polarity at the primary of transformer. This automatically resets the transformer hence eliminates the use of tertiary winding. This reduces the boot print of the circuit.

The converter voltage might be able to range from $12.6 \mathrm{~V}$ to $25.2 \mathrm{~V}$, ensuring that the converter can perform either with one or two battery cell in series, making the converter suitable even in the condition of one cell with low charge up to the situation where two batteries are fully charged. The current can assume values from almost zero (embracing batteries almost completely charged, which lead current close to zero) to $3 \mathrm{~A}$, that corresponds to a situation where 4 batteries in parallel are draining a C-rate slightly greater than $0.1 \mathrm{C}$ (which in the case of CP175 batteries corresponds to $0.72 \mathrm{~A}$ ).

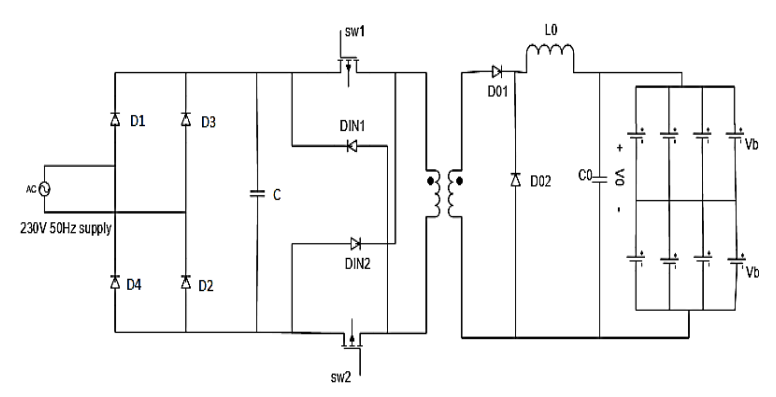

Fig 2.Proposed circuit

\section{B. Battery charging}

The sole purpose of using a battery is its capability of storing energy with minimum losses. Here lead-acid battery of $12 \mathrm{~V}$ and $7.5 \mathrm{Ah}$ has been used for simulation. For charging a lead-acid battery, a well-matched charger should be used because the capacity or life of the battery is influenced by temperature, charge, voltage, and other parameters. One of the methods most commonly used, due to its ease of implementation, is the hybrid method CC/CV (constant voltage and constant current) shown in Figure 1. This method comprises two charge stages. First, the charger provides constant current charging to the battery until the voltage at its terminals reaches a set value, usually stated as float voltage value (approximately2.1V/cell). The charging current is limited to $0.1 \mathrm{C}$ of durability purpose. Once the battery reaches the rated voltage, the charging current reduces to zero slowly until the battery is fully charged. Therefore, the voltage regulation is an important aspect of the constant voltage charge.

\section{MATHEMATICAL ANALYSES}

Output voltage is given by (1)

$$
V o=V s \times D\left(\frac{N 1}{N 2}\right)_{(1)}
$$

Duty cycle D is taken to be $50 \%$

Inductor value is given by (2)

$$
L_{\min }=\frac{(1-D) R}{2 f}
$$

Where $\mathrm{L}_{\min }$ is the minimum inductance required for continuous current. In practice, a value of inductance greater than $\mathrm{L}_{\min }$ is desirable to ensure continuous current and $\mathrm{f}$ is the operating frequency, here the operating frequency is $100 \mathrm{kHz}$ so that the noise interference can be reduced.

The inductor $\mathrm{L}_{\mathrm{o}}$ is given by (3);

$$
L_{o}=1.25 \times L_{\min }(3)
$$

The output voltage ripple is given by (4);

$$
\Delta V_{o}=\frac{V_{o}(1-D)}{8 L C F^{2}}
$$

$\mathrm{V}_{\mathrm{o}}$ is the peak-to-peak ripple voltage at the output,

Capacitance in terms of specified voltage ripple is given by $(5)$;

$$
C=\frac{1-D}{8 L\left(\frac{\Delta V_{o}}{V_{O}}\right) f^{2}}
$$

TABLE I CONVERTER DESIGN PARAMETER

\begin{tabular}{|l|l|l|}
\hline \multirow{2}{*}{$\begin{array}{l}\text { Sl. } \\
\text { No. }\end{array}$} & \multicolumn{2}{|c|}{ Designed parameters } \\
\cline { 2 - 3 } & Description & Value \\
\hline 1 & Input voltage & $\mathrm{V}_{\mathrm{RMS}}=230 \mathrm{~V}$ \\
\hline 2 & Output voltage & $\mathrm{V}_{\mathrm{O}}=25.2 \mathrm{~V}$ \\
\hline 3 & Frequency & $\mathrm{f}_{\mathrm{S}}=100 \mathrm{kHz}$ \\
\hline 4 & Output capacitor & $\mathrm{C}_{\mathrm{O}}=2 * 470 \mu \mathrm{F}$ \\
\hline 5 & Inductor & $\mathrm{L}_{\mathrm{O}}=42.5 \mu \mathrm{H}$ \\
\hline
\end{tabular}

\section{SIMULATION RESULTS}

Before implementing any hardware model, the development of a software model is necessary as it reduces the time of trial and error and helps to get the exact values of the components for implementing in practical. Hence 
MATLAB/SIMULINK software is used to design the C. prototype of specified parameter for the double ended forward converter. The parameters used to design double ended forward converter.

\section{A. Open loop simulation model}

A MATLAB Simulink model of open loop double ended forward converter is shown in figure 4.1. All the component blocks are readily available in Simulink library. In primary side an ideal $230 \mathrm{~V} 50 \mathrm{~Hz}$ AC supply. Both the MOSFETs are operated simultaneously. The gating pulse given to these MOSFETs are given through simple PWM technique. The duty cycle of $80 \%$ is given here. The working frequency is of $100 \mathrm{kHz}$.

The transformer used here is two winding linear transformer with a nominal voltage of $500 \mathrm{~W}$ and frequency of $100 \mathrm{kHz}$.

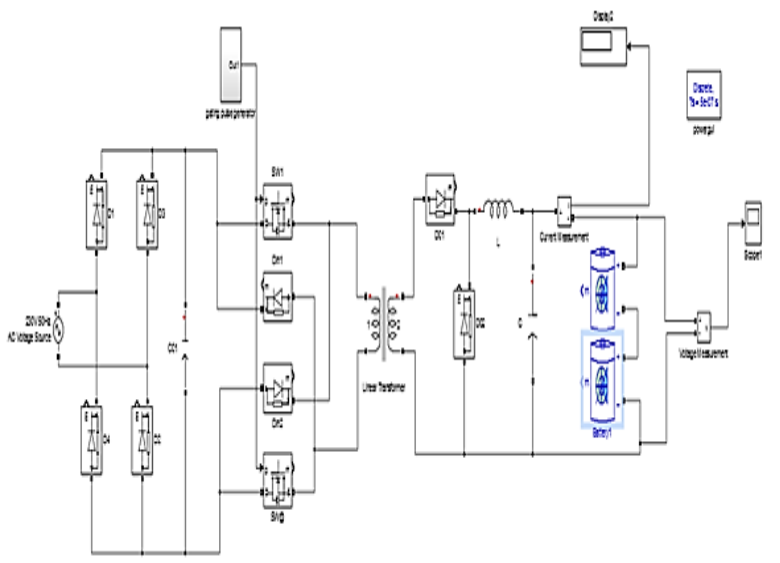

Fig.2.Open loop MATLAB Simulink model.

B. Closed loop simulation model

A closed loop double ended forward converter is shown in figure 4.2. The modelling of closed loop converter is same as that of open loop as it is done for the same parameter. Here the duty cycle is controlled in closed loop. It is done by program.

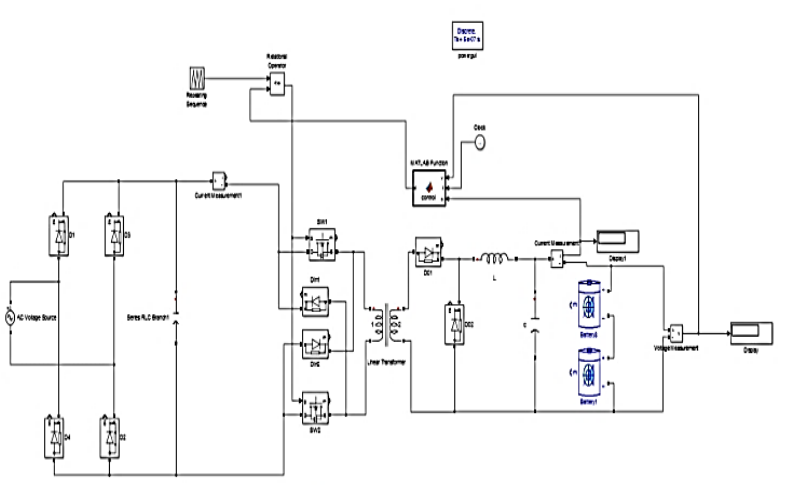

Fig. 3.Closed loop Simulink model open loop simulation results

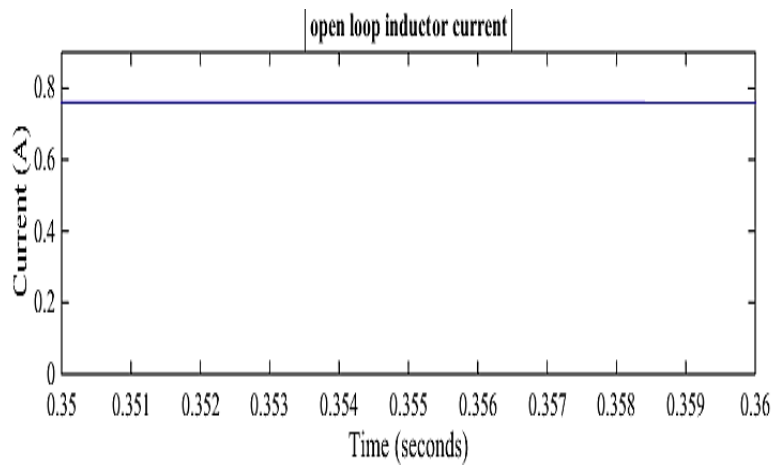

Fig.4.Open loop output voltage

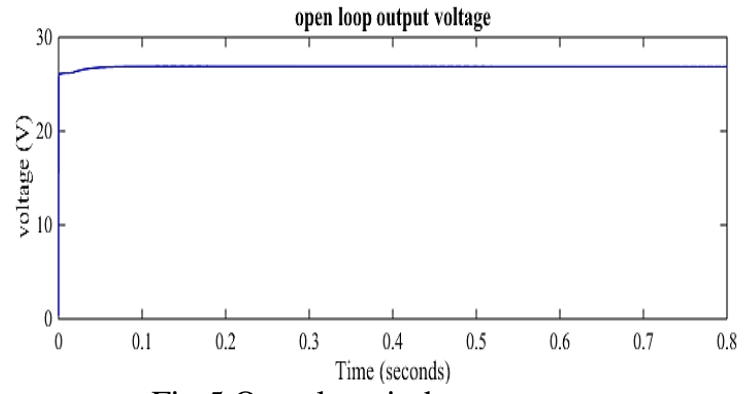

Fig.5.Open loop inductor current

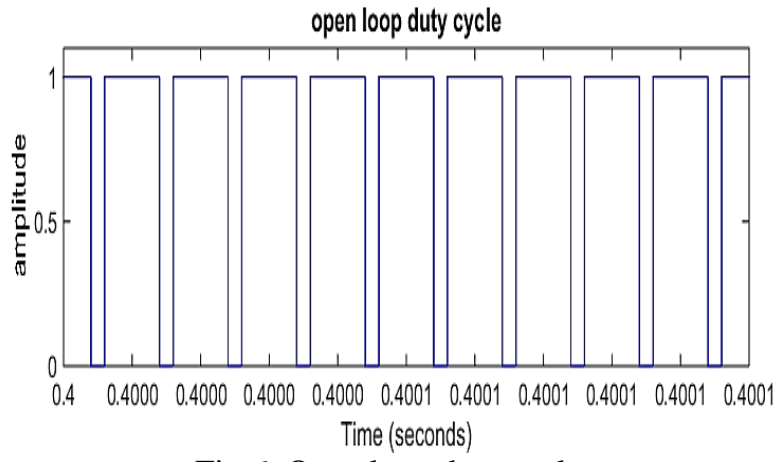

Fig.6. Open loop duty cycle

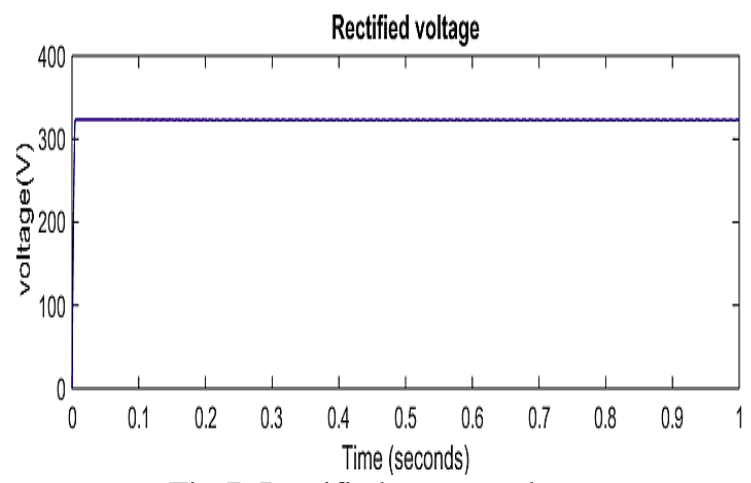

Fig.7. Rectified output voltage

D. closed loop simulation results

Output characteristics when battery is charged up to $60 \%$ 
International Journal of Innovative Research in Electrical, Electronics, Instrumentation and Control Engineering

NCAEE 2017

National Conference on Advances in Electrical Engineering

NMAM Institute of Technology, Nitte

Vol. 5, Special Issue 2, April 2017

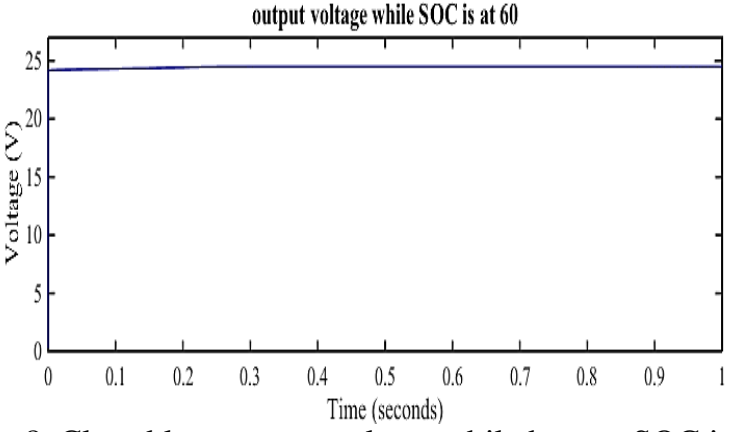

Fig.8. Closed loop output voltage while battery SOC is at $60 \%$

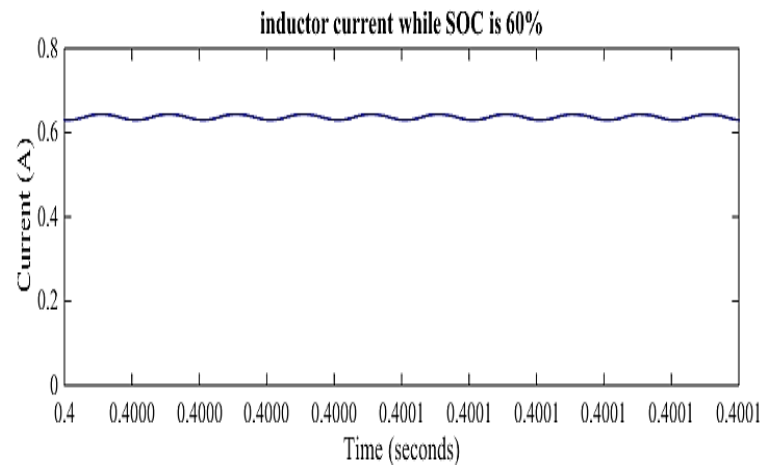

Fig.9. Closed loop inductor current while SOC is $60 \%$

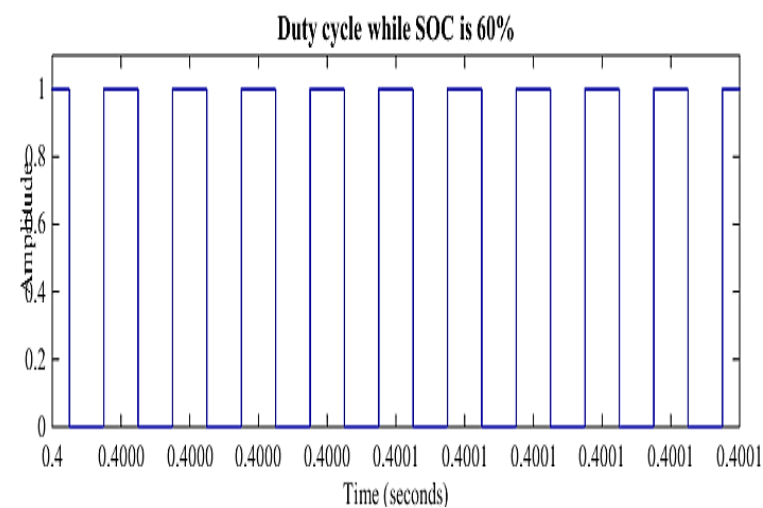

Fig.10. Duty cycle while SOC is $60 \%$

Output characteristics when battery is charged up to $99 \%$

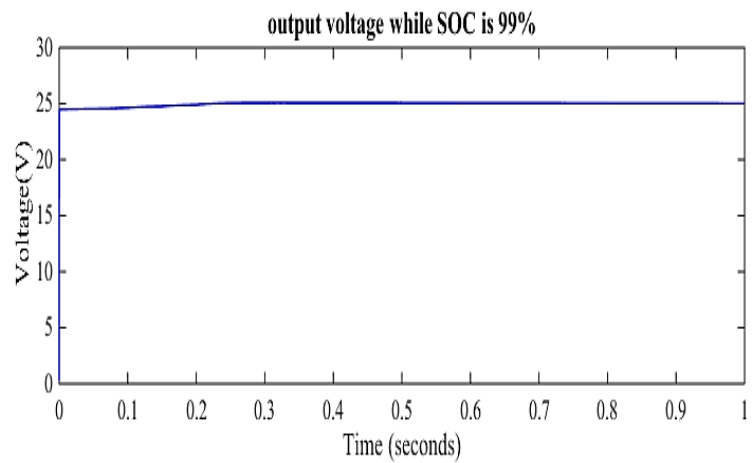

Fig.11. Output voltage while battery SOC is at $99 \%$

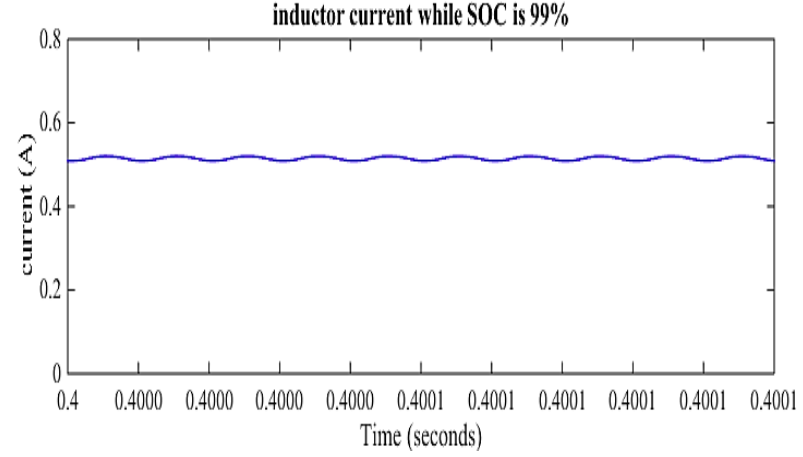

Fig.12. Inductor current while battery SOC is at $99 \%$

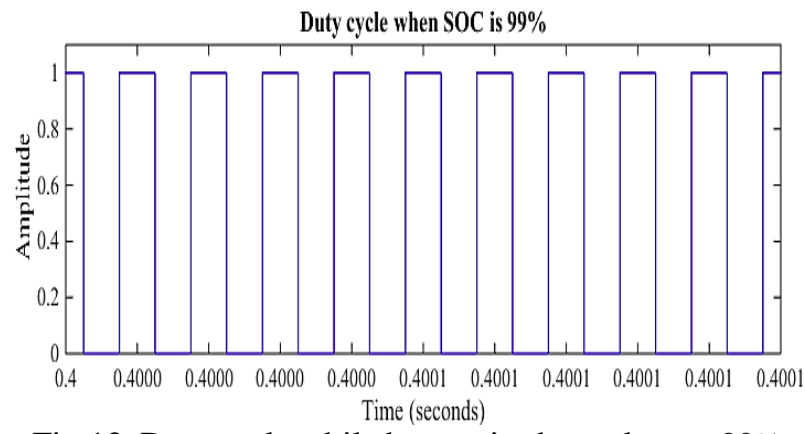

Fig.13. Duty cycle while battery is charged up to $99 \%$

Output characteristics when battery is charged up to $100 \%$

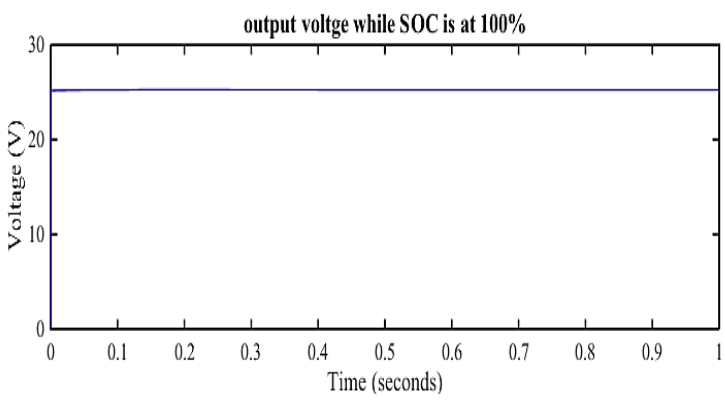

Fig.14. output voltage while battery SOC is at $100 \%$

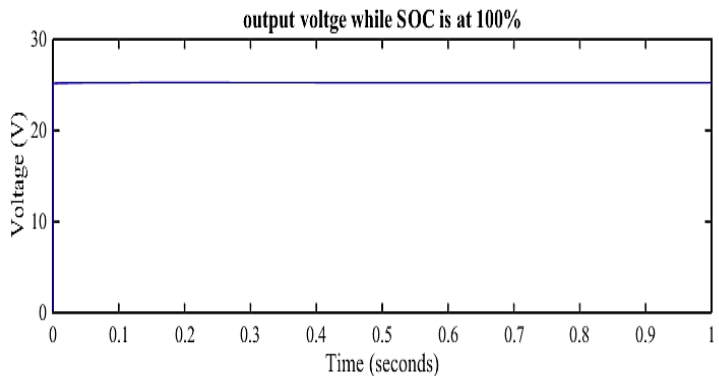

Fig.15. Inductor current while battery SOC is at $100 \%$

\section{CONCLUSION}

This paper shows the steps to build a double ended forward converter used for battery charging purpose. This converter can achieve the proposed objective. The 
simulation results of the converter operating in maximum power show that it complies to the operating requirements. From the closed loop simulation results, it is clear that this converter is suitable for battery charging. Thus, simulation results obtained, the double ended forward converter presents itself as a good solution for charging array of lead acid battery, or even a single battery.

\section{ACKNOWLEDGMENT}

Authors gratefully acknowledge the support received from R\&D Centre, Nitte, NMAM Institute of technology, Nitte Education Trust and VTU, Belagavi in carrying out the research work.

\section{REFERENCES}

[1] ChrystianLenonRemes , Murilo Brunel Rosa "A Two- Switch Forward Converter Application For Battery Charging" 1Santa Catarina State University (UDESC), Joinville - Santa Catarina, Brasil 2Regional University of Blumenau (FURB), Blumenau Santa Catarina, Brasil..

[2] [2] H. Rahimi-Eichi, U. Ojha, F. Baronti, M.-Y. Chow, "Battery Management System: An Overview of its Application In The Smart Grid And Electric Vehicles", IEEE Industrial Electronics Magazine, pp. 4-16, June 2013.

[3] C.-S. Leu, "A Novel Forward Configuration for Off-line Applications:Two-Switch Built-in Input Filter Forward Converter (2SBIFFC)", IEEE Power Electronics Section, pp. 1035-1040, 1996.

[4] I. N. Haq, E. Leksono, M. Iqbal, F. N. Soelami, Nugraha, D. Kurniadi, B. Yuliarto, "Development of Battery Management System for Cell Monitoring and Protection", in IEEE International Conference on Electrical Engineering and Computer Science, pp. 203-208, 2014

[5] M. K. Kazimierczuk, Pulse-width Modulated DC-DC Power Converters, 1st ed., John Wiley \& Sons, Inc., Wright State University, Dayton, Ohio, USA, $2008 . \quad$ [5] M.Prudík,P.Vorel,“AdvantagesofUsingTwo-Switch Forward Converter for High-Voltage Applications", in International Symposium on Power Electronics, Electrical Drives, Automation and Motion, pp. 326- 330, 2012.

[6] Panasonic, NCR18650, NNP series Datasheet, Panasonic Corporation Energy Company, Osaka, Japan, 2010.

[7] R. W. Erickson, D. Maksimovic, Fundamentals of Power Electronics, 2nd ed., Kluwer Academic Publishers, New York, N.Y., 2000.

[8] Thirugnanam, E. R. J. T. P., M. Singh, P. Kumar, "Mathematical Modeling of Li-Ion Battery Using Genetic Algorithm Approach for V2G Applications", IEEE Transactions On Energy Conversion, vol. 29, no. 2, pp. 332-343, June 2014.

[9] I. Barbi, Projeto de FontesChaveadas, Author's Edition, Florianópolis, Brazil, 2001.

[10] JC. L. Remes, R. Sebem, M. S. M. Cavalca, "Algoritmos BioInspiradosAplicadosaoAjuste de um Regulador Linear Quadrático", in Anais do CongressoBrasileiro de Automática, pp. 2909-2915, 2014. 